\title{
Lived-knowledge: A Concept Analysis
}

Caroline Mwangi ${ }^{1}$, Deidra Allen ${ }^{2}$ and Sharon L. Van Sell ${ }^{3, *}$

${ }^{1}$ Graduate Nursing Program, Texas Woman's University, United States of America

${ }^{2}$ Graduate Nursing Program, Texas Woman's University, United States of America

${ }^{3}$ Professor, The Houston J. and Florence A. Doswell College of Nursing, Texas Woman's University, United States of America

\begin{abstract}
An individual's thought processes and decision making are guided by the information learned from the time of birth until death. The various experiences and education received throughout a lifetime along with genetic predisposition contribute to the development of a person's knowledge. The knowledge acquired from different sources throughout the lifespan merge to create an individual's lived-knowledge. Lived-knowledge plays an important role in establishing the attitudes, decision making, values, beliefs, and other thought processes that make an individual unique. Consequently, lived-knowledge not only influences the personal life of an individual, but it also affects the person's professional practice as well. For example, the success of the advanced practice nurse (APN) is dependent on the effectiveness of clinical skills and decision making developed from formal education. Additionally, APNs must incorporate past experiences as a means to building a positive rapport and identifying with their patients, making, lived-knowledge crucial to the development and success of APN practice. A concept analysis of lived knowledge utilizing Walker and Avant's eight step methodology was conducted to clarify the meaning of the concept lived-experience in the context of the APN.
\end{abstract}

Publication History: Received: April 04, 2018 Accepted: June 21, 2018

Published: June 23, 2018

Keywords:

Advanced practice nurse, Experiences, Knowledge, Lived, Lived-knowledge

\begin{abstract}
Lived-knowledge was a concept not easily defined by traditional methods such as dictionaries or encyclopedias. The concept of livedknowledge combined two separate concepts lived and knowledge, words more commonly used in the English language easily defined with everyday reference sources. In the absence of a formal definition of lived-knowledge, a review of the literature was necessary to develop a description and definition of the concept, leading to a formal concept analysis.
\end{abstract}

Lived-knowledge described as education and experiences gained throughout life up to the present moment in time that contributed to an individual's overall knowledge. Although limited literature was available on the concept, lived-knowledge have had a great impact on the practice of advanced practice nurses (APNs) and healthcare in general.

APNs earned the educational qualifications to assess, diagnose, and prescribe treatments for patients under their care. Although some may have believed that education was the sole contributing factor to APN practice, other information gained throughout life was just as influential to lived-knowledge. According to Stanley [1], caregivers with experiences related to their patients-lived-knowledge were perceived by the patients as having a better understanding of their issues (p.262). The positive experiences constituting lived-knowledge enhanced the ability of APNs to identify with patients, contributing to building a positive rapport that encourages healing. Conversely, negative aspects of lived-knowledge caused prejudices, poor communication, and decreased understanding on the part of APNs.

The healthcare system has relied on the lived-knowledge of care providers to conduct research and develop policies and procedures to combat illness and disease among patients. The reputation and survival of healthcare organizations have been dependent upon the educational expertise incorporated into the lived-knowledge of employees. In addition, healthcare systems have counted on staff to meet the needs of patients and families through lived-knowledge, described by Johansson and Lindahl [2] as knowing oneself and using internal knowledge caregivers possess without actively thinking about it (p. 239). Furthermore, patients have not played a passive role in healthcare because they have lived-knowledge that contributed to their perceptions, attitudes, and degree of understanding.
The authors chose lived-knowledge as a concept after a brief discussion and a review of the literature. The concept inspired by the joy of working with the elderly population and an interest in the experiences and information older people has acquired throughout the years and can share with others. Additionally, history offered another area of interest to the concept analysis group because of information gained from the past. The authors believed that livedknowledge was important due to its influence on APN practice and the operation and success of the healthcare system.

\section{Concept Analysis}

\section{Aim of the concept analysis}

After deciding upon a concept to analyze, the second step in the concept analysis of lived-knowledge was determining the purpose of the analysis. According to Walker and Avant [3], the aim or purpose of the analysis was to answer the question, "Why am I doing this analysis?" (p.161). The main purposes of the present concept analysis were to clarify the meaning of the concept of lived-knowledge and introduce the concept to nursing and other disciplines. The concept of lived-knowledge may have been new to nursing, but the concept has been used by APNs unknowingly.

As registered nurses (RNs) have translated to the role of APNs, their life experiences, informal and formal learning, awareness, and understanding have defined their practice. Van Sell and Kalofissudis [4] explained nursing practice in terms of nursing knowledge and the ability of each nurse to integrate and synthesize that knowledge through cognitive, psychomotor, affective, and spiritual domains of self. APNs

"Corresponding Author: Dr. Sharon L. Van Sell, The Houston J. and Florence A. Doswell College of Nursing, 5500 Southwestern Medical Avenue, \#7209, Dallas, Texas, 75235-7299, USA, Tel: 1-864-275-3527, Fax: 214-689-6539; E-mail: svansell@twu.edu

Citation: Mwangi C, Allen D, Van Sell SL (2018) Lived-knowledge: A Concept Analysis. Int J Nurs Clin Pract 5: 283. doi: https://doi.org/10.15344/2394 4978/2018/283

Copyright: (C) 2018 Van Sell et al. This is an open-access article distributed under the terms of the Creative Commons Attribution License, which permits unrestricted use, distribution, and reproduction in any medium, provided the original author and source are credited. 
gained formal and informal knowledge during their schooling to become APNs; as a result, their lives enrich with new experiences, a history of RN experience, and years of personal experience. APNs' awareness of lived-knowledge enhanced patient care and assisted APNs to connect with their patients on a personal level. That was how APNs have been able to assist patients in identifying their own livedknowledge and determining how they can put their lived-knowledge into use.

One way of identifying lived-knowledge was to acknowledge past experience from childhood to the present. To this end, group therapy has been a successful treatment modality in the discipline of psychology and psychiatry. Patients shared their experiences to encourage other group members, relieve anxiety and shame, console others, and feel a sense of belonging. APNs have helped their patients to do the same.

Most Texas colleges and universities require two years of $\mathrm{RN}$ experience before the candidate applies to a university for graduate education required for an APN licensure. APN students attain work and personal experience during the two years of employment that translates into the role of APN. According to Benner [5], the experience was important for skill acquisition and development of competency, and experience was valuable during role transition. Cusson and Strange [6] found that nurse practitioners (NPs) with less staff nurse experience required more time to adapt to the new role. The importance of APNs' lived-knowledge ultimately defined their practice.

\section{Relating theory to practice}

Theories have been developed especially for healthcare to improve the quality of care and ensure use of best practice. The concept of lived-knowledge is limited in the discipline of nursing and needs more analysis before the development of a theory. According to Walker and Avant [3] concept analysis alone did not provide useful theories for nursing education, research, or practice. Only when the concepts interconnect to each other could useful theories result

\section{Uses and Definitions of Lived-knowledge}

The concept lived-knowledge required separating into two separate concepts. Lived and knowledge comprised the foundation of livedknowledge and was easily defined. Dictionary.com [7] defined lived as "having life, a life, or lives, as specified" (para. 1) and was derived from the word life, which had origins in Middle English (1350 A.D.1400 A.D.). Additionally, the Merriam-Webster Online Dictionary [8] further defined lived as "having a life of a specified kind or length" (para. 2). The definitions were similar in that each referred to the act of existence for a duration of time.

The second portion of the concept, knowledge, was described by the Cambridge Academic Content Dictionary [9] as "awareness, understanding, or information that has been obtained by experience or study, and that is either in a person's mind or possessed by people generally" (para. 1). Like the first word of the concept, lived, knowledge had roots from 14th century Middle English. The Merriam-Webster Online Dictionary [10] defined knowledge as "the fact or condition of knowing something with familiarity gained through experience or association" and an "acquaintance with or understanding of a science, art, or technique."
Unlike lived and knowledge, lived-knowledge was not defined by dictionary sources; therefore, the authors of the present concept analysis utilized a review of the literature to develop a description of lived-knowledge. Lived-knowledge was determined to be a concept that morphed out of the primary term, knowledge, specifically acquired throughout the lifespan. The importance of lived-knowledge lay in the concept's effect on current decision making and behavior in the person's personal and professional life. In other words, an individual's lived-knowledge caused either a positive or a negative impact on other people with whom each came in contact.

The literature review revealed that the concept of lived-knowledge was utilized previously by sociology, psychiatry, and family science as well as nursing. The nursing profession expressed lived-knowledge in the context of the nurse-patient relationship. For example, Johansson and Lindahl [2] described lived-knowledge as not always being a need "for new external knowledge but knowledge of oneself as a person" (p. 2039). In fact, the authors noted, "[Lived-knowledge] is concerned with the intuitive quiet knowledge that nurses possess without thinking about it [2]. This means 'having good self-knowledge and knowledge of others' (p. 2039) [2]. Furthermore, Iaquinta and Larrabee [11] explained lived-knowledge as the sharing of lived moments between the nurse and the patient using "dynamic dialogue" (p.280). Furthermore, "Articulation between nurses and patients exemplify [ies] that 'nursing is an experience lived between human beings.' Finding meaning in life is a primary motivation for being... This meaning is specific, unique, and individually experienced" (p. 280) [11].

Social sciences, especially social work, similarly defined livedknowledge as a counselor's (or carer's) increased understanding of a client's circumstances based on having previous experience with a similar situation. Consequently, counselors with similar livedknowledge were more valued by clients because the counselors had "survived" a comparable situation (p. 262) [1]. Additionally, psychiatry and family science characterized lived-knowledge as integrated experiences from a person's past $[12,13]$. Lived-knowledge mentioned in one source from the social psychology discipline, provided a vague and poorly defined explanation of the concept. Regardless of the discipline, obvious similarities and relationships were evident among the descriptions of lived-knowledge.

\section{Attributes}

Defining attributes [3] were the process of determining the characteristics most closely associated with the concept of livedknowledge. The attributes of lived-knowledge developed from the separate terms of lived and knowledge.

The part of the concept, lived, was made up of the following attributes: (a) being alive, (b) life experiences, and (c) human being. The Merriam-Webster Online Dictionary [14] defined alive as "having life; not dead or inanimate" (para 1.). Similarly, Dictionary.com [15] identified alive as "having life; living; existing; not dead or lifeless" (para 1.). Based on the definitions from both dictionaries, being alive was determined to be the most important attribute for the concept of lived-knowledge because an individual must be a living organism to experience life.

The second attribute of lived was life experiences-situations that occurred with "knowledge gained through living" [16]. Kuyavaand Rubim Pedro [17] reported lived experiences were situations having 
implications on an individual's "way of life" (p.321). Additionally, perceptions were that formal education was the only influencing factor in the development and success of a profession; however, the experiences of an individual's personal and professional life were just as influential. For instance, the success of the APN's practice was contingent upon the nurse's ability to isolate positive life experiences for use in building rapport with patients.

The final attribute for lived-knowledge identified was the human being. The Cambridge Academic Content Dictionary [18] defined a human being as "a person" (para 1). However, the Oxford English Dictionary Online [19] described the human being as "a man, woman, or child of the species Homo sapiens, distinguished from other animals by superior mental development, power of articulate speech, and upright stance" (para. 1). APNs and patients constituted human beings who possessed lived knowledge; therefore, APNs and patients must have been able to treat one another with the respect and dignity expected if placed in similar circumstances. As a case in point, "nurses and nurse practitioners should listen attentively to the patient's own story about his or her illness" (p.288) [11]. Moreover, the view of nursing is an "experience lived between human beings" (p.280) [11].

The attributes of knowledge were informed learning, experience, awareness, and understanding. Informed learning was the comprehension of information provided to an individual. Bruce and Hughes [20] explained informed learning as "a pedagogical construct attending to information use and comprehension" (para. 1). The Merriam-Webster Online Dictionary [21] characterized experience as "direct observation of or participation in events" (para. 1a) to obtain information. The personal and professional experiences conveyed by the APN in practice influenced the unique quality of the APN's nursing care; therefore, APNs must incorporate positive experiences into their routine. The third attribute of knowledge was awareness, described by Dictionary.com [22] as "the state or condition or being aware; consciousness" (para. 1). APNs used awareness to gain knowledge through assessments and observations and as a means of learning new tasks and procedures. Awareness has been the conduit for which APNs obtained information. Finally, understanding encompassed the process of comprehending information. The ability to become APNs would have been virtually impossible without the ability to incorporate and comprehenddaily information.

\section{Model Case}

According to Walker and Avant [3], a "model case should be a pure case of concept, a paradigmatic example, or a pure exemplar" (p. 170). Next is an example of the model case containing all of the attributes of the concept lived-knowledge.

Patricia was a 48-year-old nurse with over 20 years of experience. In the last 15 years, Patricia worked at the same telemetry unit, and she has enjoyed being a staff nurse rather than a charge nurse. Patricia was also active outside her unit by serving on the hospital's safety committee, organizing social events for her unit, and assisting in her church's health clinic. Unfortunately, Patricia underwent coronary artery bypass graft (CABG) two years ago resulting from severe atherosclerosis. Patricia has provided care to post-CABG patients for several years, but the experience did not alleviate her anxiety about the surgery. Her surgery was successful, and Patricia was able to return to work after a few months.

Int J Nurs Clin Pract

ISSN: 2394-4978
When Patricia returned to work, her assignment was a 58-year-old female patient, Katrina, who was scheduled for CABG the next day. Katrina was very anxious about the surgery, and even after watching videos and receiving extensive teaching, she still felt anxious. Patricia decided to use her personal experience with CABG surgery to help alleviate Katrina's anxiety. Patricia explained to Katrina what Patricia had gone through step-by-step during her surgery. Patricia also showed the patient her scars and encouraged Katrina, telling the patient she would be able to return to work after major surgery.

The model case study illustrated the critical attributes of livedknowledge. Patricia used her informed learning to take care of the patient, her experience to alleviate the patient's fear of surgery, her awareness of anxiety before surgery, and her understanding of the patient's concerns.

\section{Borderline case}

Walker and Avant [3] noted, "Borderline cases are those examples or instances that contain most of the defining attributes of [the] concept being examined but not all of them" (p. 170). Also, these cases tended to be inconsistent in some way from the concept under consideration [3]. An example of a borderline case for the concept of lived-knowledge follows.

Mary was a 48-year-old nurse in a medical unit. Mary was ambitious and strove to acquire a high level of knowledge. She precepted new nurses and student nurses because learning and teaching were among her passions. Mary had come from a family of two sisters and two brothers. Her mother had a long history of diabetes, and after 20 years of illness, she suffered several diabetes complications including end renal disease and stroke. Mary's mother went for dialysis three times a week, passing away after two years of treatment. Mary was very involved with her mother's care and had taken personal leave from work to care for her mother. After Mary had lost her mother, she was able to cope well and return to work in a few weeks.

Mary's assignment was a 52-year-old woman admitted for shortness of breath secondary to generalized edema. The patient, Glenda, had several illnesses in her medical history including diabetes and hypertension. After an initial assessment by the attending physician, a nephrologist consult was made due to Glenda's metabolic acidosis. After a few days of treatment, the patient did not respond well, and dialysis was recommended to alleviate shortness of breath. Glenda was very adamant that dialysis was not an option for her even with family intervention. Mary was very familiar with the dialysis procedure and felt comfortable explaining the dialysis process. Mary shared her mother's experience with dialysis as well as her experience taking care of her mother. Mary listened to Glenda, the patient, as Glenda voiced her concern and fear of dialysis. The patient valued her quality of life, and she reported that having treatment three times a week produced a poor quality of life. Mary respected Glenda's wishes even though she did not agree. Mary suggested consulting palliative care to the attending physician because Glenda expressed her value of the quality of life.

The palliative care nurse visited with the family and the patient and recommended hospice. Glenda's health was deteriorating every day, and her shortness of breath was worsening. A social worker arranged home hospice, and the patient was able to go home. Glenda was treated with morphine as needed for shortness of breath, and her symptoms were well-controlled by the hospice nurse. After a few

IJNCP, an open access journal Volume 5. 2018. 283 
weeks, Glenda passed away comfortably at home surrounded by her family. Mary was saddened by her patient's death and believed that the patient would have lived longer if she had agreed to dialysis.

Some of the attributes of lived-knowledge applied in this borderline case. Mary's experience with other dialysis patients and her mother enabled her to explain to her patient what to expect with dialysis. Her informed learning from school, and continued education made her confident discussing renal disease and dialysis. Mary's lack of personal experience with dialysis treatment decreased her awareness and understanding of the fear and concern about having dialysis. Even though Mary had taken care of her mother and other patients, she did not know what the actual feelings of going through dialysis. She did not understand why the patient declined dialysis treatment because Mary lacked awareness of the suffering that came with dialysis.

\section{Contrary case}

Walker and Avant [3] described a contrary case as one that had the absence of the concept (p. 166). An example of a contrary case for the concept of lived-knowledge follows.

A 78-year-old male patient, Craig, seen at his local community health clinic after complaining of indigestion and left arm pain for the last 3-4 day. Craig was brought back to the examination room by the nursing assistant to obtain the patient's vital signs, which were as followed: (a) blood pressure $=168 / 97$, (b) respiration $=24$, (c) temperature $=98.4^{\circ} \mathrm{F},(\mathrm{d})$ pulse $=110$, and (e) oxygen saturation $=91 \%$ on room air. Craig's usual healthcare provider was Jennifer, the APN who has been working at the clinic for over ten years. On this visit, Craig saw April, an APN from a staffing agency.

April entered the room and quickly greeted the patient without any eye contact. She huffed a little and checked her cell phone, giggled, then turned to the laptop to access the electronic medical records. April proceeded quickly to ask Craig the routine questions, but she never bothered to look up from the computer. Craig had difficulty responding to the questions due to shortness of breath (SOB). The APN had difficulty understanding the patient because of his frequent pauses in speaking to catch his breath; consequently, she requested that he repeat most of his answers, causing him more discomfort. Due to an inability to understand Craig, April discontinued the assessment questions and decided to copy the data from the patient's last visit. April performed a brief visual and physical assessment before exiting the room to develop her plan of care for Craig. April used the copied data from Craig's previous visit because he was seen several times previously by Jennifer for GERD. Since she copied the data on Craig, April would be able to leave early to go and check on her grandmother who was in the hospital suffering from a second cardiac arrest.

Craig was sent home with a prescription for Omeprazole $10 \mathrm{mg}$ by mouth daily for 14 days with instructions to return to the clinic in 2 weeks if the condition did not resolve. Approximately two days later, April was contacted by her agency with questions about her care of Craig. April learned that Craig was admitted to the local hospital with a diagnosis of acute myocardial infarction (MI) the night after she saw him in the clinic. Craig had unfortunately passed away the following day after going into cardiac arrest.

The contrary case exemplified an absence of the attributes related to lived-knowledge. Additionally, even though April's grandmother had recently suffered a cardiac arrest, April was unable to use her life experience to identify with or understand her patient. Furthermore, the APN did not use her informed learning or previous experience to recognize the symptoms of the impending MI. The outcome for Craig could have been entirely different if April had applied her livedknowledge. Consequently, the patient lost his life, and the APN had to suffer the negative consequences of providing poor quality care.

\section{Antecedents}

The antecedents of a concept "are those events or incidents that must occur or be in place prior to the occurrence of the concept" (p.167) [3]. The antecedents of lived were God's energy, creation, and birth.

The belief in God as one's Father and the creator of all things has been shared by Christians throughout the world. An example of God's ability and energy was evident in the Bible verse, "then the Lord God formed the manfrom the dust of the ground. He breathed the breath of life into the man's nostrils, and the man became a living person."

Creation was closely tied to God's energy for those with spiritual beliefs based on the teachings of the Bible. However, for those individuals with a belief in evolution as the source of the human being, creation was attributed to a change in the gene pool of a population from generation to generation by such processes as mutation, natural selection, and genetic drift [23]. Creation was explained further by the Merriam-Webster Online Dictionary [24] as "the act of making or producing something that did not exist before: the act of creating something" (para. 1). Regardless, of an individual's beliefs, creation was found to be an essential antecedent of the concept to livedknowledge because an individual must exist for lived-knowledge to occur.

Birth was the last antecedent of lived and was defined by the Oxford English Dictionary Online [25] as "the emergence of a baby or other young from the body of its mother; the start of life as a physically separate being" (para. 1). The entry of a new living human being into the world was the starting point for experiences and learning, eventually developing into the person's lived-knowledge.

The antecedents of knowledge were a certification as an APN, inexperience, prior information, storytelling/folklore, and setting. The RN seeking to become an APN first had to obtain a higher level of education-at least a master's degree-before taking the state board examination for certification as an APN. Once achieving certification, the nurse was permitted to practice as a mid-level care provider.

An absence of information and understanding were characteristics of the novice without knowledge-inexperience. Once obtaining comprehension of new data, the person was recognized as having acquired more information than he or she previously had. Expert staff nurses wish to provide advanced practice nursing care, however, to care for patients as a provider requires additional expertise and knowledge as well as a graduate nursing degree.

The Merriam-Webster Online Dictionary [26] defined storytelling as telling stories (para. 1), and folklore [27] was "traditional customs, tales, sayings, dances, or art forms preserved among a people" (para. 2(1)). Many families have had older family members who have shared stories with younger generations. Additionally, thoughts 
and behaviors displayed by other family members were sometimes adopted by the younger individuals in the family. A professional adult needed to become aware of negative and positive familial influences. More specifically, APNs should have avoided the use of behaviors and thoughts that might have possible negative impacts on their practice.

Finally, the setting was described by the Merriam-Webster Online Dictionary [28] as the location in which experiences and learning took place. Settings encompassed both formal and informal areas where knowledge was acquired. The location of the lived-knowledge acquisition was less important than the content obtained. APNs received education and experiences in the clinical setting as well as in institutions of higher learning. Although personal education and experiences in a less-structured setting also occurred, the information still played a role in the development of APNs' practice.

\section{Consequences}

Walker and Avant [3] explained, "consequences are useful in determining often neglected ideas, variables, or relationships that may yield fruitful new research directions" (p.168). The consequences of lived were determined to be aging, death, and reflexivity. The consequences of knowledge were wisdom, insight, and change.

Aging was one of the consequences of lived; the aging process started from birth and progressed every second. Perception of aging was different among individuals. "Society, culture and individual characteristics and capabilities shape the meaning of successful aging independently" [29]. As result of aging, APNs encountered different experiences that improved their practice and enhanced their knowledge.

Death was another consequence of lived. Death considered by many as end-of-life but death also viewed as a translation of another life. Death has occurred at any point of living, but the lived duration has not determined when death will have occurred. APNs' understanding of death as a consequence of lived enabled them to address end-of-life and quality of life matters. The multidisciplinary staff was involved with the end and quality of life, but APNs could have been the leaders of the group because APNs were expected to have a higher understanding of the topic.

The last consequence of lived was reflection. As a result of reflection, most individuals expect self-satisfaction or regrets. APNs were aware of patients' reflection and their contribution to their health. Patients' reflection of life had an effect on physical, emotional, and psychosocial health. Most patients who have had regrets or prior trauma were likely to have difficulties with their health compared to self-satisfied individuals. According to Celano, Daunis, Lokko, Campbell, and Huffman, et al. [30], stress, anxiety, and post traumatic disorders had detrimental effects on cardiac health. Some of the physiological effects on cardiac health were autonomic dysfunction, platelet dysfunction, inflammation, and endothelial dysfunction. APNs' understanding of the association between negative reflection and health was important during diagnosis and treatment.

Change was a consequence of knowledge. Informal or formal knowledge was mostly likely to result in change. After APNs had attained their formal education, their level of knowledge was expected to change along with the quality of their practice. Meredith [31] discussed managing change in healthcare:
Change is [an] inevitable fact of life [on] both personal and organizational levels. An effective change strategy for transforming practice is one that involves those who will be implementing the change. Individuals need to be enabled to go through a period of transition in order to come to terms with major change. (p. 45).

Wisdom was another consequence of knowledge. Wisdom regarded as an indispensable attribute of an educator, whose responsibility was to guide understanding and to apply knowledge. Wisdom was the knowledge passed from experienced nurses to less experienced nurses. As APNs graduated and assumed the role of advanced practice, they gave up their role of expert RNs and became novice nurse practitioners. After several years of experience, the APNs acquired knowledge and skills; as a result, experienced APNs were considered as having wisdom.

Finally, insight was the last consequence of knowledge. Insight was the ability to understand relationships that shed light or helped solve problems. After obtaining knowledge, APNs had insight into their new role of advanced practice.

\section{Empirical referents}

The final step in the concept analysis of lived-knowledge was the identification of the empirical referents. Empirical referents were categories of the actual phenomena that demonstrated the existence or presence of the concept in its contextual framework [3]. Experience was an empirical referent for the concept of lived-knowledge. Negin, Coffman, Vizintin, and Raynes-Greenow [32] conducted a study on the grandmother's influence on the mother's breast feeding practices. "In many societies around the world, older women are seen as owners of traditional knowledge and cultural history which has strong community significance" (p. 1) [32]. The study conducted with 13 newborns whose grandmothers assisted with caregiving. The investigation included a range of time points of exclusive breastfeeding from 1 week to 6 months. Of the 13 participants, 8 of the newborns breast fed due to the grandmother's influence. Two participants showed no influence, and the other three breastfed, but for less than six weeks. Breast feeding for the first six months of an infant's life has shown potential to reduce mortality and morbidity. The grandmothers' experience was passed on to the next generation, contributing to knowledge, wisdom, and change.

\section{Impact of the Concept of Lived-knowledge}

The concept of lived-knowledge played a large role in healthcare without the realization of many healthcare professionals. Livedknowledge was the summation of educational and life experiences that made an individual unique. The concept set the tone for the type of practice the APNs had; therefore, recognizing positive influences was important. The use of positive characteristics of lived-knowledge led APNs to become successful providers. Early recognition of traits assisted nurses in the development of effective decision making that, in turn, led to good nurse-patient relationships built on mutual respect. Lived-knowledge affected healthcare from the perspective of the patient as well. Patients who received care from APNs also had experiences with previous providers, acute illnesses, and chronic diseases affecting patients' perception of care providers. APNs must, therefore, use the lived-knowledge that encourages a sense of empathy and comfort to promote feelings of confidence and ease in the patient. 


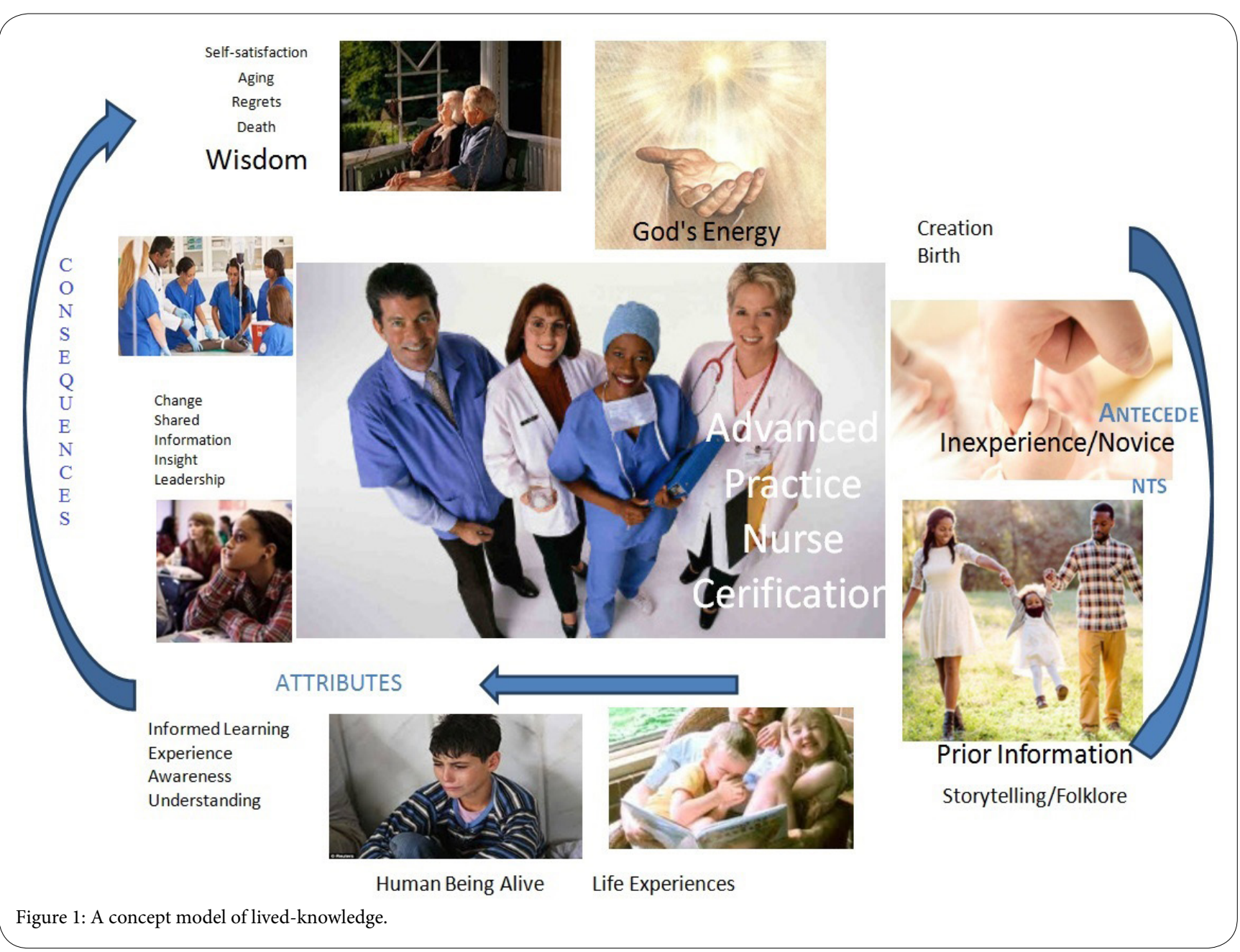

\section{Discussion}

Figure 1 is the model of the concept lived-knowledge. The model begins at the top on the right side with the antecedents (for both "lived" and "knowledge"), the first being the photograph depicting God's energy. The blue arrow demonstrates the direction to go from the antecedents that represent the beginning of life, "birth" and "creation." A young person is a novice with inexperience that receives storytelling and folklore in various settings. The attributes in relation to the APN is the acquisition of the certification (after receiving informed learning), use of prior knowledge as a registered nurse before gaining experience, understanding, and awareness of the new profession. "Lived" is represented by the concepts: human being, being alive and life experiences (the blue arrow pointing to the left representing the transition from antecedents to attributes). Finally, the ascending blue arrow demonstrates the consequences of "lived" as follows: self-satisfaction, reflexivity, aging, death, and regrets. Additionally, the consequences of "knowledge" included changed, self-satisfaction, shared information, insight, leadership, and wisdom.

The APN must recognize that lived-knowledge plays a large role in his or her professional practice. Incorporation of the positive aspects of lived-knowledge is essential for the APN to identify with patients and provide the best care, ultimately leading to a successful personal practice.

\section{Competing Interests}

The authors, Mwangi and Allen declare that they have no competing interests.

Dr. Van Sell declares she is co-author of the e-book The Evolving Essence of the Science of Nursing: The Complexity Integration Nursing Theory.

\section{Funding}

This article was published with support from Texas Woman's University Libraries' Open Access Fund.

\section{References}

1. Stanley N (2007) Young people's and carers' perspectives on the mental health needs of looked-after adolescents. Child and Family Social Work 12: $258-267$.

2. Johansson K, Lindahl B (2011) Moving between rooms-Moving between life and death: Nurses' experiences of caring for terminally ill patients in hospitals. J Clin Nurs 21: 2034-2043.

3. Walker LO, Avant KC (2011) Concept analysis. In M. Conner (Ed.), Strategies for theory construction in nursing (pp.156-179). Upper Saddle River, NJ: Prentice Hall.

4. Van Sell SL, Kalofissudis IA (2002) The evolving essence of the science of nursing: Complexity integration nursing theory (E-book). Athens, Greece: ICU Web Journal. 
Citation: Mwangi C, Allen D, Van Sell SL (2018) Lived-knowledge: A Concept Analysis. Int J Nurs Clin Pract 5: 283. doi: https://doi.org/10.15344/23944978/2018/283

5. Benner PA (1984) From novice to expert: Excellence and power in clinical nursing practice. Menlo Park, CA: Addison-Wesley.

6. Cusson RM, Strange SN (2008) Neonatal nurse practitioner role transition: The processof re-attaining expert status. J Perinat Neonatal Nurs 22: 329337.

7. Lived (2016) In Dictionary.com.

8. Lived (2016) In Merriam-Webster online dictionary.

9. Knowledge (2016) In Cambridge Academic Content Dictionary.

10. Knowledge (2016) In Merriam-Webster online dictionary.

11. laquinta ML, Larrabee JH (2004) Phenomenological lived experience of patients with rheumatoid arthritis. J Nurs Care Qual 19: 280-289.

12. Chefetz RA (2005) From the guest editor. Psychiatric Annals 35: 622-624.

13. Lam CM, Kwong WM (2012) The "paradox of empowerment" in parent education: A reflexive examination of parents' pedagogical expectations. Family Relations 61: 65-74.

14. Alive (2016) In Merriam-Webster online dictionary.

15. Alive (2016) InDictionary.com

16. Experience (2016) In Merriam-Webster online dictionary.

17. Kuyava J, Rubim Pedro EN (2014) The voice of children who live with HIV on implications of the disease in their daily life. Investigacion y Educacion En Enfermeria 32: 317-325.

18. Humanbeing (2016) In Cambridge academic content dictionary.

19. Humanbeing (2016) In Oxford English Dictionary online (2nd ed.).

20. Bruce CS \& Hughes HE (2010) Informed learning: A pedagogical construct attending simultaneously to information use and learning. Library and Information Science Research 32: A2-A8.

21. Experience (2016) In Merriam-Webster online dictionary.

22. Awareness (2016) In Dictionary.com.

23. Creation (2016) In Dictionary.com

24. Creation (2016) In Merriam-Webster online dictionary.

25. Birth (2016) In Oxford English Dictionary online (2nd ed.)

26. Storytelling (2016) In Merriam-Webster online dictionary.

27. Folklore (2016) In Merriam-Webster online dictionary.

28. Setting (2016) In Merriam-Webster online dictionary.

29. Zanjari N, SharifianSani M, HosseiniChavoshi M, Rafiey H, \&Mohammadi Shahboulaghi F, et al. (2016) Perceptions of successful ageing among Iranian elders. Int J Aging Hum Dev 83: 381-401.

30. Celano CM, Daunis DJ, Lokko HN, Campbell KA, Huffman JC, et al. (2016) Anxiety disorders and cardiovascular disease. Curr Psychiatry Rep 18: 101

31. Meredith L (2008) Managing change. In Mason-Whitehead E, Mcintosh A, Bryan A, \& Mason T (Eds.), Key Concepts in Nursing (ch. 31). London, UK Sage UK.

32. Negin, J, Coffman, J, Vizintin, P, Raynes-Greenow, C (2016) The influence of grandmothers on breastfeeding rates: A systematic review. BMC Pregnancy and Childbirth 16: 1-10. 